\section{European complaint}

\section{mechanisms vary widely}

$\mathrm{A}$ $t$ times, the impulses are at odds. Treating patients' complaints seriously while not losing sight of the rights of doctors and other medical personnel can be tricky, but the course taken speaks volumes about commitment to accountability and democratic reform.

A CMAJ canvas of how complaints are handled in England, France, Denmark and Sweden indicates processes vary widely within Europe, in implementation and degree of transparency, much as in Canada (CMAJ 2008;178[I]: I4-6) and the United States (CMAJ 2008; I78[6]:67I-2).

Like their North American counterparts, European systems leave first contact in the hands of local physicians or administrators. What comes next, though, varies widely. England's process operates through both state and semi-private channels. As in France, it involves both the national medical association and a state institution. In contrast, less populous countries with greater regional autonomy, like Sweden and Denmark, often have systems that are simpler, with fewer avenues for achieving resolution but better guarantees for financial compensation.

In England, it's hoped most problems can be resolved at first contact. Typically, whether in England, Scotland, Wales or Northern Ireland, National Health Service trusts have appointed managers to field complaints and help resolve local disputes. General practitioners, dentists, pharmacists and opticians are all also required to designate someone to field and oversee complaints made against them. Moreover, conciliation is a legally mandated option for all National Health Service facilities and independent general practitioners.

The process gets trickier if local conciliation or institutional investigation fails to resolve an issue.

In such cases, complaints are then streamed along 2 different paths. If they are deemed to be serious enough to affect a doctor's registration, they are

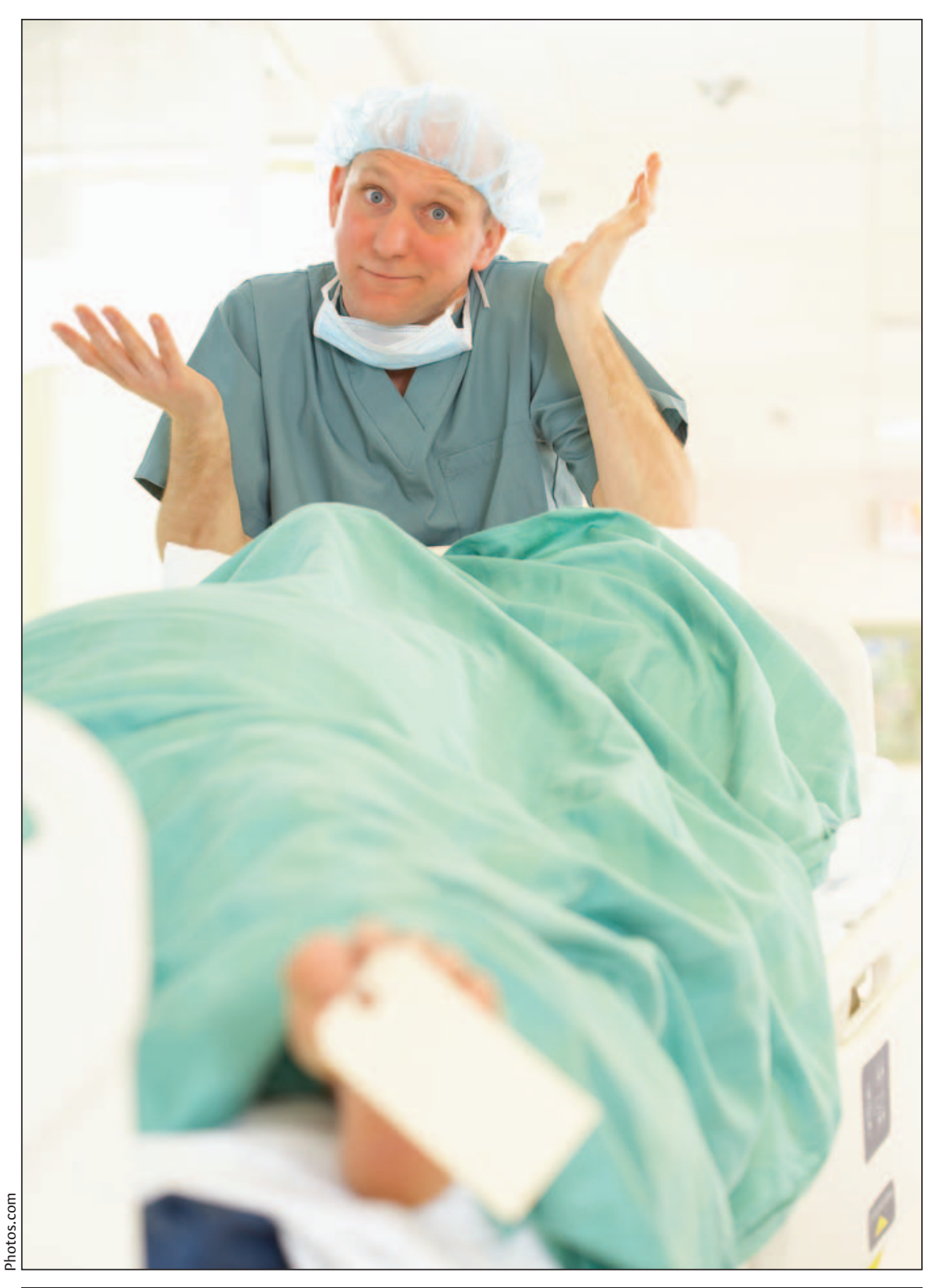

Several European nations automatically award compensation for medical mishaps caused by physicians.

shuffled along to the licensing body for physicians, the General Medical Council. If not, they follow a process in which they are reviewed by the National Health Service.

That split is a relatively recent phenomenon, the product of a complaintssharing arrangement reached in 2005 between General Medical Council President Sir Graeme Catto and the National Health Service.

Prior to that agreement, all complaints were dealt with by the General Medical Council as an issue of registra- tion and as a result, most fell by the wayside as the Council only investigated complaints that it deemed serious. Chief Executive Officer Finlay Scott acknowledges that this led to a limited number of investigations, in which the outcome was invariably a "warning."

In cases where the Council which is responsible for handling complaints in all of England, Scotland, Wales and Northern Ireland - now reviews a complaint, options include dismissing it, issuing a warning or 
convening a fitness-to-practice panel comprised of medical and lay personnel. The quasi-judicial panel hears licensing arguments, pro and con. If it finds the doctor's fitness to practise impaired by misconduct, poor performance or ill health, it may place conditions on his or her practice, or suspend the doctor's licence for up to 3 years. Typically, a panel's findings affects separate malpractice or civil suits for financial damages.

In terms of public reporting of General Medical Council decisions, the agency's list of registered practitioners records the names of all doctors who have held licences at any point since the online registry was instituted in October 2005, including those now licensed, those no longer licensed, and those who have received warnings or had conditions placed on their licences. In the past, the Council had the option of erasing a doctor's name from the registry.

A slightly more convoluted process ensues for complaints that were unresolved by local mediation and are streamed to the National Health Service. The service's Health Commission, a mix of non-medical and state medical employees, conducts a review of the case. Its options include referral back to the local organization, referral to the General Medical Council or direct action.

If the complainant remains dissatisfied, or if the Commission determines that the physician or institution failed to cooperate during the process, the final resort is an independent National Health Service Ombudsman. Although the Ombudsman's office has no binding, legal authority to enforce recommendations, including those for compensation, it claims that "they are almost always followed."

In all instances involving National Health Service review, existing regulations prevent patients from using the process if they intend to seek compensation through the courts. So they must either initiate civil action for financial damages or make a National Health Service complaint in hopes of systemic improvements. Patient-empowerment organizations, such as Help the Aged and Action against Medical Accidents, contend this policy is "illogical and unfair," so it is now under review.

France's system also operates on several levels. The country's Conseil National de l'Ordre des Médecins provides medical practice standards and licenses physicians, while the Commissions régionales de conciliation et d'indemnisation des accidents médicaux, des affections iatrogènes et des infections nosocomiales is mandated with organizing "conciliation" measures.

But there's a significant difference. Unlike the General Medical Council, the Conseil can award financial compensation to victims of adverse health incidents. Like England's Council, it also maintains a publicly accessible database of licensed physicians. In neither case, however, does that registry always include those licensed in other nations, as European Union right-to-movement laws don't obligate physicians to register with the medical association of the country in which they're practising. And they often don't.

That creates the potential for abuse, as a doctor who loses the right to practise in one country can simply set up

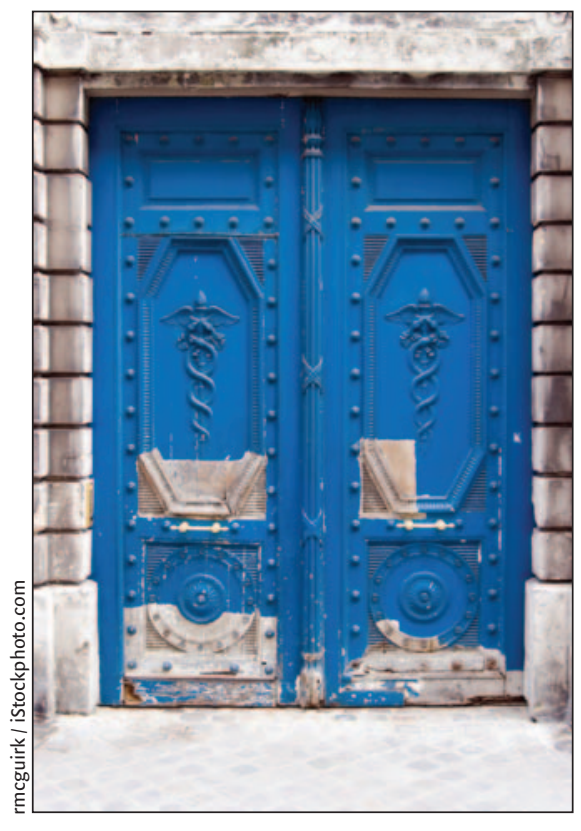

Over a 5-year period in France, only $5 \%$ of claimants received awards under the nation's no-fault compensation plan for victims of adverse medical events. In 2006, the underspending topped 11 million euros. shop in France or elsewhere. Reliable data on such cross-border doctoring is only slowly becoming available and nations don't share complaint histories.

The Conseil does not even show complaint outcomes on its website, offering only such information in its registry as physicians choose to provide. And while the Conseil can revoke or suspend licences, its process isn't quasi-judicial, as in England. Rather, cases work their way through the disciplinary sections of regional councils. Regional sanctions can include warnings, reprimands, temporary suspension of licences and "striking [doctors] from the rolls of the order."

Neither patients nor individual physicians can appeal regional decisions. Only the doctor's union, select state officials and the regional body itself can undertake appeals, which is a far more rigid and hierarchical approach than that of England.

The Conseil also offers patients little information about how to go about making complaints. But the quasigovernmental Haute Autorité de Santé and the Commissions régionales de conciliation et d'indemnisation can hear some patient complaints and refer others to the proper authority. The Haute Autorité de Santé (National Health Authority) is also charged with facilitating compensation for victims of adverse medical events "whether there was fault or absence of fault."

Theoretically, France's no-fault compensation scheme, which was implemented in conjunction with nofault patient insurance in 2002, should make the traditional link between complaints mechanisms and litigation a thing of the past.

But France may be having implementation issues. In 2006, the scheme underspent its budget by II million euros. It paid out to only 532 of roughly Io 800 claimants from 2002-2006.

In Sweden, by way of contrast, compensation is prompt and uncomplicated. But, as a consequence, a complaints process is practically non-existent. "Our health care is democratically controlled," and as a result, politicians generally argue that such a process is "unnecessary," says Arne Björnberg, former chief executive 
officer of the Swedish National Pharmacy Corporation Apoteket AB.

Denmark takes a more Canadianstyle approach, in that regulation of physicians isn't directly coupled with compensation. "We have split the judgment of complaints totally from the compensation side," Paul Bartels, medical director of the region of Middle Jutland, says. He adds that Danish patient insurance functions in such a way that if patients prove harm caused by any actions "below the standard of a very experienced doctor," they are compensated.

The Danish system locates a patient advisor's office in each hospital or regional administration to serve as a sort of on-site ombudsman. Patients can complain about doctors or even broader issues like waiting times.

Beyond that lies the National Complaints Board, where panels of medical peers, lay people and a real judge issue rulings on whether a physician breached the law.

The rulings, which don't include financial damages, are offered on 3 levels.

The first, a statement of censure, essentially says that a doctor hasn't practised according to good principles. After 3 such reprimands, he or she is identified on an Internet registry as a "bad practitioner." Bartels says doctors find that "extremely degrading," although there are typically no financial or employment consequences.

A finding of negligence comes with both a fine and a professional evaluation. It can result in job loss, and frequently does.

The Board's third and final level of judgement is a rare finding of manslaughter, which results in the matter being promptly kicked over to the criminal courts.

Bartels says the flaw in the system is that it only allows for complaints to be made about individual medical professionals and not about a hospital or other institution, which might, for example, be running a medical service without adequate nursing staff or equipment. He explains: "You cannot bring the system to trial ... [which] is not cohesive with the patient safety movement." - Ira Allen, Paris, France

DOI:I0.I503/cmaj.080527

\section{Foreign-trained doctors}

\section{dominate pilot project}

S keptics call it a tremendous waste of medical talent, while proponents argue it could become a viable career path for international medical graduates who are unable to obtain residencies.

Neither conclusion is exactly what might have been expected from a series of Ontario pilot projects evaluating the use of physician assistants in hospital and other health care settings (CMAJ 2007;177[5]:177). Yet, given that 39 international medical graduates were among the 59 people hired as physician assistants in 4 Ontario demonstration projects, it may someday become the norm.

Dr. Joshua Thambiraj, president of the Association of International Physicians and Surgeons of Ontario, surmises that many international medical graduates opted to become involved in the projects because they simply lost hope of practising in Canada.

"The doctors that they have taken to be physician assistants have the knowledge and the capability to be fullfledged physicians," Thambiraj says. "Having said that, if the route to becoming a physician is so difficult it is almost impossible to get in, then this is a form of solution."

Hundreds of international medical graduates who had passed the Medical Council of Canada exams with excellent grades were contacted about the possibility of working as physician assistants.

The program has provided a second career option for international medical graduates, says Dr. Joshua Tepper, assistant deputy minister of Health $\mathrm{Hu}-$ man Resources Strategy Division in the Ministry of Health and Long-Term Care.

"They will continue to have this other career opportunity, which would in no way suggest that we are limiting the number of opportunities for direct entry into the medical profession. It's just a complementary alternative."

Ontario now has 200 training and assessment positions annually for international medical graduates. Thambiraj estimates that of the 1800 members in his association, up to 800 are

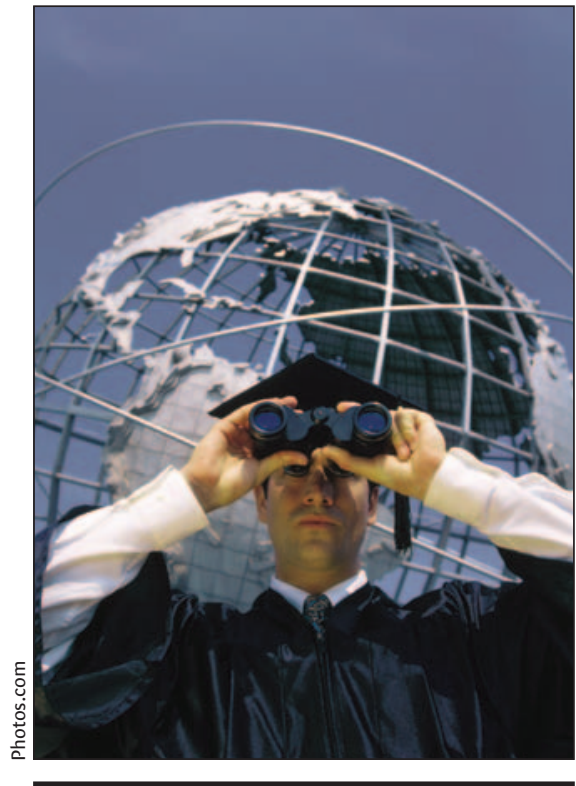

The Ontario government actively recruited international medical graduates for 4 pilot projects to ascertain the value of physician assistants.

doctors who have passed all the necessary exams but have been unable to get residencies or assessments.

International medical graduates involved in the pilot programs were required to undergo a 9-step conversion that includes 4 months of training. Maurice Chapman, president of the Canadian Association of Physician Assistants, says the results will need to be studied before decisions are made on whether to include or pursue international medical graduates for future assistant positions, if they become available. The I-year emergency room pilot has been completed; the 3 other pilots will wrap up by Mar. 3I, 2010.

Using international medical graduates as physician assistants in the future could impact plans to establish educational programs at Canadian universities to develop a steady stream of suitably trained individuals. The University of Manitoba will launch Canada's first training program for civilian physician assistants in September 2008, while Tepper says the ministry is now negotiating with 2 Ontario medical schools to establish programs. - Benjamin Magnus, Ottawa, Ont.

DOI:Io.I503/cmaj.0806oI 